\title{
AN EXPERT SYSTEM FOR DIAGNOSTICS AND ESTIMATION OF STEAM TURBINE COMPONENTS' CONDITION
}

\author{
KONSTANTIN E. ARONSON, BORIS E. MURMANSKY, ILIA B. MURMANSKII \& YURI M. BRODOV \\ Ural Federal University named after the First President of Russia B.N. Yeltsin, Ekaterinburg, Russia
}

\begin{abstract}
This article describes an expert system of probability type for diagnostics and state estimation of steam turbine technological subsystems' components. The expert system is based on Bayes' theorem and permits one to troubleshoot the equipment components, using expert experience, when there is a lack of baseline information on the indicators of turbine operation. Within a unified approach, the expert system solves the problems of diagnosing the flow steam path of the turbine, bearings, thermal expansion system, regulatory system, condensing unit, and the systems of regenerative feed-water and hot water heating. The knowledge base of the expert system for turbine unit rotors and bearings contains a description of 34 defects and 104 related diagnostic features that cause a change in its vibration state. The knowledge base for the condensing unit contains 12 hypotheses and 15 pieces of evidence (indications); the procedures are also designated for 20 state parameters' estimation. Similar knowledge bases containing the diagnostic features and fault hypotheses are formulated for other technological subsystems of a turbine unit. With the necessary initial information available, a number of problems can be solved within the expert system for various technological subsystems of steam turbine unit: for steam flow path, it is the correlation and regression analysis of multifactor relationship between the vibration and the regime parameters; for thermal expansion system, it is the evaluation of force acting on the longitudinal keys depending on the temperature state of the turbine cylinder; for condensing unit, it is the evaluation of separate effect of the heat exchange surface contamination and of the presence of air in condenser steam space on condenser thermal efficiency performance, as well as the evaluation of term for condenser cleaning and for tube system replacement. With the lack of initial information, the expert system formulates a diagnosis and calculates the probability of faults' origin.
\end{abstract}

Keywords: diagnostic, diagnostic features, expert system, evidence, faults, hypotheses, steam turbine.

\section{INTRODUCTION}

At present, the research on the state parameters of turbine unit equipment, forecasting of their changes and determination of their residual life has become widespread [1-3]. In world practice, technical condition monitoring and equipment diagnostics are carried out by the centers operating at the manufacturing plant or in a large operating organization. At the same time, the working methods of these centers at the enterprises have been developed individually for many years and are a commercial secret. Steam and gas turbine manufacturers in the territory of Russia currently do not have such centers $[4,5]$. Some works of certain enterprises are known concerning individual areas of diagnosis [6-8]. The lack of common approaches to the development of diagnostic tasks for various elements of equipment makes it difficult to implement them at thermal power plants. Expert systems (ES) seem to be the most ambitious approach for many diagnostic tasks. This methodology is connected with a huge volume of factors of steam turbines operating.

ES are very advantageous for steam turbine unit (STU) diagnosis. These systems are designed to solve problems that are difficult to formulate. The ES is based on Bayes' theorem and permits one to troubleshoot the equipment components when there is a lack of baseline information on the indicators of turbine unit operation. The system also employs the experience of experts. The inaccuracy and lack of initial information are taken into account by 
probabilistic methods using Bayes' formula. The value of each piece of evidence is determined by the Naylor method [9-12].

\section{METHODOLOGY}

An ES comprises a knowledge base and an information processing algorithm. The knowledge base contains information about STU failures as fault hypotheses and a table of evidence. The a priori probability of fault hypotheses and the evidence value are determined by the experts. The ES analyzes the evidence. If information is missing, the system receives it from a user or out of a database. The user sets the values of pieces of evidence and the ES calculates a posteriori probabilities of hypotheses and forms a conclusion about the cause of failure. The system then makes recommendations to the staff about how to eliminate the malfunction.

According to Bayes' theorem [9], a posteriori probability of the hypothesis is calculated by the formula:

$$
\mathrm{P}(\mathrm{H} / \mathrm{E})=\frac{\mathrm{P}(\mathrm{E} / \mathrm{H}) \cdot \mathrm{P}(\mathrm{H})}{\mathrm{P}(\mathrm{E})},
$$

where $\mathrm{P}(\mathrm{E} / \mathrm{H})$ is the probability of evidence $\mathrm{E}$, if the hypotheses $\mathrm{H}$ is true; $\mathrm{P}(\mathrm{H})$ stands for $a$ priori probability of the hypotheses $\mathrm{H}$; and $\mathrm{P}(\mathrm{E})$ stands for the probability of evidence $\mathrm{E}$.

$\mathrm{P}(\mathrm{E})$ is determined by the formula of total probability:

$$
\mathrm{P}(\mathrm{E})=\mathrm{P}(\mathrm{E} / \mathrm{H}) \times \mathrm{P}(\mathrm{H})+\mathrm{P}(\mathrm{E} / \overline{\mathrm{H}}) \times \mathrm{P}(\overline{\mathrm{H}}),
$$

where $\mathrm{P}(\mathrm{E} / \overline{\mathrm{H}})$ is the probability of evidence $\mathrm{E}$, if the hypotheses $\mathrm{H}$ is false:

$$
\mathrm{P}(\overline{\mathrm{H}})=1-\mathrm{P}(\mathrm{H}) \text {. }
$$

From (1) and (2), a posteriori probability of the hypothesis is calculated:

$$
\mathrm{P}(\mathrm{H} / \mathrm{E})=\frac{\mathrm{P}(\mathrm{E} / \mathrm{H}) \cdot \mathrm{P}(\mathrm{H})}{\mathrm{P}(\mathrm{E} / \mathrm{H}) \cdot \mathrm{P}(\mathrm{H})+\mathrm{P}(\mathrm{E} / \overline{\mathrm{H}}) \cdot \mathrm{P}(\overline{\mathrm{H}})} .
$$

The ES comprises the knowledge bases designed for turbine flow part, for turbine bearings, for system of thermal expansions, for automatic regulatory system, for condensing unit, and for the systems of regenerative feed-water heating and hot water heating. For diagnostics, knowledge bases for various defects were collected. They were divided according to the turbine subsystem: vibration diagnostics, control system, heat expansion system, auxiliary equipment, etc. Each subsystem contains its own list of defects and diagnostic features. For example, the knowledge bases of the ES for vibration diagnostics of turbine rotors, bearings and other components include a description of 34 defects and 104 diagnostic features. These defects cause a change of vibration state of the turbine unit. All defects are divided into two groups: defects that occur during the turbine operation and defects added during turbine mounting and repair.

The defects of turbine unit mounting and repair are identified in the analysis of start-stop actions. The defects of operation are revealed in the analysis of turbine component vibration, vibration changes or the relationship of vibration to the turbine operation.

A number of connections are used to diagnose the system of steam distribution and turbine regulatory system (see Table 1). On the basis of these relationships the parameters of Table 2 are calculated. 
When diagnosing turbine regulatory systems, the ES also makes use of the dynamic response of the actuators - servomotors and slide valves.

An ES consists of three main interconnected components: a knowledge base, an output mechanism and a database that provides diagnostic solutions, similar to how experts do it. The database is designed to store initial and intermediate data. It contains all the necessary data for diagnosis, obtained by measurements and observations.

The knowledge base in the ES is intended to store long-term data describing the area under consideration and the rules that, when applied to the initial data, lead to the solution of the problem. Expert knowledge is presented in the knowledge base in the form of rules [11, 13]. The output mechanism interprets the rules and uses the facts of the knowledge base to solve the problems posed. It makes a diagnosis based on the information contained in the database.

Available ES can be divided into three types: logical ES, cause-effect ES and 'intelligent' ones. Logical models are presented as tables of faults, which list the signs of possible faults (usually the parameters that exceed beyond the set point). In a broader sense, the emphasis is only set on the principle of tolerance control of parameters, while the description of malfunctions can be quite complicated.

Cause-effect ES (PSM) are models that reflect the interrelations between the processes and conditions of the diagnostic object in case of malfunction occurrence and development (or the qualitative relationship between the malfunction causes and their consequences). PSM can have a hierarchical structure, which shows at each level in a graphical form the relationship of various faults leading to more serious malfunctions.

Table 1: Parametric relationships generated in the diagnosis of the turbine automatic regulatory (TAR) system.

\begin{tabular}{|c|c|}
\hline № & Name \\
\hline 1 & Turbine steam flow rate - setting of high-pressure part servomotor \\
\hline 2 & Turbine steam flow rate - turbine capacity \\
\hline 3 & $\begin{array}{l}\text { Settings of high (medium) pressure control valves - settings of high (medium) } \\
\text { pressure part servomotor }\end{array}$ \\
\hline 4 & $\begin{array}{l}\text { Steam pressure beyond the valves of high (medium) pressure part - settings of high } \\
\text { (medium) pressure part servomotor }\end{array}$ \\
\hline 5 & $\begin{array}{l}\text { Force of high (medium, low) pressure part servomotor - settings of high (medium, } \\
\text { low) pressure part servomotor }\end{array}$ \\
\hline 7 & $\begin{array}{l}\text { Force of medium (low) pressure part servomotor - steam pressure in a chamber of } \\
\text { process or heating steam extraction }\end{array}$ \\
\hline 8 & $\begin{array}{l}\text { Steam pressure in control stage (or first stage) chamber - settings of high-pressure } \\
\text { part servomotor }\end{array}$ \\
\hline 9 & Steam pressure in control stage (or first stage) chamber - turbine steam flow rate \\
\hline 10 & $\begin{array}{l}\text { Settings of steam stop valve autoactuators - oil pressure above the autoactuators' } \\
\text { slide valves }\end{array}$ \\
\hline 11 & $\begin{array}{l}\text { Settings of steam stop valve autoactuators - oil pressure below the autoactuators' } \\
\text { slide valves }\end{array}$ \\
\hline
\end{tabular}


Table 2: Main features for diagnostics and adjustment of the TAR system.

\begin{tabular}{|c|c|c|}
\hline № & Feature name & $\begin{array}{l}\text { Electrohydraulic system of regulation and } \\
\text { protection characteristic, determined from the } \\
\text { recorded dependencies }\end{array}$ \\
\hline \multirow{3}{*}{1} & \multirow{3}{*}{$\begin{array}{l}\text { Static characteristic of rotation } \\
\text { speed control (RS) }\end{array}$} & Degree of frequency response variations (FR) \\
\hline & & Degree of frequency regulation insensitivity \\
\hline & & $\begin{array}{l}\text { Areas and values of the local non-uniformity of } \\
\text { frequency regulation }\end{array}$ \\
\hline \multirow{4}{*}{2} & \multirow{4}{*}{$\begin{array}{l}\text { Cam-operated steam distribu- } \\
\text { tion device (CSD) and nozzle } \\
\text { unit performances }\end{array}$} & CSD technical condition \\
\hline & & Quality of the control valve setting adjustment \\
\hline & & Nozzle unit condition \\
\hline & & Flow part condition (salt fouling) \\
\hline \multirow[b]{2}{*}{3} & \multirow{2}{*}{$\begin{array}{l}\text { Force margins of regulatory } \\
\text { system servomotors }\end{array}$} & $\begin{array}{l}\text { Identification of unstable operation areas of auto- } \\
\text { matic regulatory system }\end{array}$ \\
\hline & & Regulation units lock detection \\
\hline \multirow{3}{*}{4} & \multirow{3}{*}{$\begin{array}{l}\text { Performances of steam stop } \\
\text { valve autoactuators }\end{array}$} & Turbine regime optimization \\
\hline & & $\begin{array}{l}\text { Technical condition of steam stop (safety) valve } \\
\text { autoactuators }\end{array}$ \\
\hline & & $\begin{array}{l}\text { Insensitivity of steam stop (safety) valve autoactua- } \\
\text { tors }\end{array}$ \\
\hline
\end{tabular}

A characteristic feature of 'intelligent' ES is, first of all, the form of diagnostic knowledge presentation. As for the fundamental capabilities of these systems, they do not differ significantly from the capabilities of ES of other types, with the exception of fuzzy logic [14]. The latter approach gives great opportunities in the analysis of complex systems because it allows one to operate with subjective assessments of an expert or user and to employ incomplete or inaccurate information.

The program shell of a probabilistic ES includes a universal information processing program based on the Bayes' formula taking into account the 'price' of each piece of evidence according to the Naylor method [11]. The specific filling of the knowledge base, that is, the formation of its content and the designation of a priori probabilities for the hypotheses and the 'price' of evidence, is carried out, as a rule, by the method of expert evaluations employing the specialists dealing with thermo-mechanical equipment of thermal power plants, thus taking into account the specific features of the equipment at a particular station.

To diagnose steam turbine subsystem parts, the ES employs various approaches, such as:

- for turbine flow part - a correlation and regression analysis of the multi-factor relationship between vibration and regime parameters;

- for thermal expansion system - the evaluation of forces acting on longitudinal keys under different temperatures of the left and right sides of turbine cylinder;

- for condensing unit - the estimation of the effect of cooling surface fouling as well as of air content in condenser steam chamber on condenser efficiency, optimization of condenser cleaning period, justification of periods of condenser tube system replacement, etc. 
The algorithms of the data analysis for defects causing the vibration are presented below. The indications of these defects are divided as follows:

- boundary group where the defect indications are determined by a measured parameter drop outside the normalized limits;

- factorial group where the defect indications are determined by an occurrence of a previously unobserved factor;

- correlation group where the defect indications are determined by a connection between the vibration and technological parameters.

Boundary indications are determined by a measured parameter drop outside the permissible limits that is beyond the zone of partial or full serviceability. As a rule, the boundaries of these zones are designated in the regulations.

Factor indications are characterized by a qualitative change in vibration parameters, for example, by the rise of rotational component of vibration in vertical or transverse direction or vibration components with frequency of $2 w, 3 w, 4 w$ and so on, by abrupt increase in high-frequency harmonics, by the emergence of new frequencies in the turbine unit vibration spectrum: frequencies from 500 to $2000 \mathrm{~Hz}$ point to leakage in regulatory system, whereas frequencies from 1000 to $1050 \mathrm{~Hz}$ point to backlash in control valves.

For the correlation indications, a change is estimated in the coefficient of correlation between the vibration characteristics and technological process parameters.

\section{APPLICATION}

The ES functioning can be described by taking a steam turbine condensing unit as an example $[15,16]$. A knowledge base for the condensing unit contains more than 30 hypotheses and 25 pieces of evidence (or indications); estimation procedures for 20 parameters of state are also specified. Tables 3 and 4 show a sample from the knowledge base.

A preliminary list of malfunction hypotheses is set up on the basis of performed investigations, statistical processing of data on equipment damage and literature data. After expert examination, the final list of hypotheses is filled in the knowledge base. The evidence list is being set up during the condenser unit operation. The measurement circuit, the results of the condenser unit tests, the operation regimes and maintenance logs are analyzed.

Then a priori probabilities of the hypotheses and evidence probabilities are entered in the table of probabilities. In addition, evidence probabilities are entered to detect the fault (to confirm the hypothesis) and not to detect the fault (reject the hypothesis). These probabilities are specified for each evidence. In the first case, the evidence probability is denoted by the superscript (+), and in the second case, by the superscript (-). Table 5 shows an example of probability table for four hypotheses and three evidences.

Malfunction evidence listed in Table 5:

1. High water heating;

2. Temperature difference between steam and cooling water outlet exceeds the norm;

3. Condenser pressure exceeds the norm.

For hypotheses, the values of the maximal and minimal probability are also evaluated. This permits one to form a justified diagnosis for limiting values of probabilities. 
Table 3: Hypotheses of condenser unit (CU) equipment malfunction.

\section{CU equipment Malfunction hypotheses}

Tube plates fouling

Overpressure in the drain pipe

Deterioration of siphon rarefaction

Cooling surface fouling on the steam side

Cooling surface fouling on the water side

Elevated quantity of induced air

Condenser

Incomplete opening of the drain valve

Elevated hydraulic resistance in the pressure line

Condensate flooding on lower tube rows

Level regulator fault

Cooling water suction in the steam space

Air suction between the condenser and condensate removal pump

Water leakage from water ejector into condenser

Improper organization of various streams discharge into condenser

Steam grates or working nozzle clogging

Inadequate flow rate of the full-flow condensate entering the ejector cooler

Cooler heat transfer surface fouling on the water side

Cooler heat transfer surface fouling on the steam side

Steam jet ejector

Steam-air mixture recirculation through one of the ejector stages

Leaks in the partitions separating the coolers

Airmeter or the exhaust pipe clogging

High temperature of the full-flow condensate

Dead air zones occurence in the drain pipe

Leakage in ejector cooler

Reduced heat exchange surface of the ejector cooler

Changes in the hydraulic regime of water reservoir

Skid of coarse gratings with aquatic vegetation and debris

Circulation path

Significant fouling of rotating grates due to late cleaning or to wash-

(geodesic height) ing device malfunction

Accumulation of air released by heating water

Incomplete opening of the drain valve

Water level lowering in the admission chamber 
Table 4: Evidence of CU equipment malfunction.

\begin{tabular}{|c|c|}
\hline CU equipment & Malfunction evidence \\
\hline \multirow{14}{*}{ Condenser } & High water heating \\
\hline & High steam pressure at the condenser inlet \\
\hline & Low flow rate of cooling water \\
\hline & High cooling water pressure at the condenser inlet \\
\hline & $\begin{array}{l}\text { Increased temperature difference between steam and cooling } \\
\text { water outlet }\end{array}$ \\
\hline & Oxygen presence in the full-flow condensate \\
\hline & Condensate overcooling $\left(t_{c}-t_{s}\right)<0$ \\
\hline & High pressure in the cooling water drain pipes \\
\hline & Low cooling water pressure at the condenser inlet \\
\hline & Low pressure in the pressure line of the circulation pump \\
\hline & High condensate hardness \\
\hline & Exhaust steam pressure is above the standard (low vacuum) \\
\hline & High hydraulic resistance of the condeser \\
\hline & High condensate level in the condenser \\
\hline \multirow{10}{*}{ Steam jet ejector } & $\begin{array}{l}\text { Pressure pulsations of steam-air mixture at the ejector inlet } \\
\text { and discharge }\end{array}$ \\
\hline & Low pressure in the pipeline upstream of the ejector \\
\hline & High pressure of the working steam upstream of the ejector \\
\hline & Increased working steam flow rate \\
\hline & $\begin{array}{l}\text { The sharp increase of the pressure in the suction chamber of } \\
\text { the ejector when the exhaust air flow is within the range cor- } \\
\text { responding to the design part of ejector performance }\end{array}$ \\
\hline & A number of ejector cooler tubes are gagged \\
\hline & High back pressure beyond the last stage of the ejector \\
\hline & Water ejection from the exhaust \\
\hline & Inlet pressure pulsations at the second and third ejector stages \\
\hline & High pressure at the ejector suction \\
\hline Circulation path & Unsatisfactory performance of the drain water siphon \\
\hline
\end{tabular}

During the ES function, it analyzes the equipment operation parameters and then, if there is lack of information, it asks the user a series of questions to make the information more precise.

Figure 1 shows the form for evidence processing. The users click the buttons 'Yes' or 'No' and so indicate the degree of confidence in their answer to the question. The program corrects the a posteriori probabilities of the hypotheses taking into consideration the degree of 
Table 5: A sample of the probability table.

\begin{tabular}{llllllllll}
\hline & \multicolumn{8}{c}{$\begin{array}{c}\text { A priori } \\
\text { proba- }\end{array}$} & \multicolumn{6}{c}{$\begin{array}{l}\text { Evidence probability for detection (non-detec- } \\
\text { tion) }\end{array}$ of failure (hypothesis) } \\
№ & Hypothesis & bilities & $\mathbf{1}^{+}$ & $\mathbf{1}^{-}$ & $\mathbf{2}^{+}$ & $\mathbf{2}^{-}$ & $\mathbf{3}^{+}$ & $\mathbf{3}^{-}$ \\
\hline $1 \quad \begin{array}{l}\text { Condenser tube } \\
\text { plates fouling }\end{array}$ & 0.5 & 0.8 & 0.2 & 0.005 & 0.005 & 0.5 & 0.005 \\
$2 \quad \begin{array}{l}\text { Overpressure in the } \\
\text { drain pipe }\end{array}$ & 0.5 & 0.8 & 0.2 & 0.05 & 0.05 & 0.5 & 0.05 \\
$3 \quad \begin{array}{l}\text { Deterioration of } \\
\text { siphon rarefaction }\end{array}$ & 0.6 & 0.1 & 0.05 & 0.05 & 0.1 & 0.05 & 0.2 \\
$4 \quad \begin{array}{l}\text { Elevated quantity } \\
\text { of induced air }\end{array}$ & 0.7 & 0.05 & 0.05 & 0.7 & 0.05 & 0.7 & 0.05 \\
\hline
\end{tabular}

confidence in the user answers. The number of such questions corresponds to the number of evidence in the database of the ES leaving the evidence already processed out.

\section{EXAMPLE}

As an example, it is here suggested to consider the diagnostics of ejector malfunction. It is known that ejector is an auxiliary equipment with a very high influence on the turbine. Ejector diagnostics is performed upon request. Most parameters (signs) are defined manually in case of usual lack of measurements. The other point is a difficulty of automation; some parameters such as knocking, cooler overflowing and others are qualitative, not quantitative.

The ejector state is defined in the operation process. For better diagnostics, there is need to provide ejector tests. Also some of the defects could be found only when dissembling the ejector. The initial data for this task are presented in Table 6 .

In the ES, the defects (malfunctions) that can occur in the ejector, as well as a priori probabilities of these defects $(\mathrm{P}(\mathrm{H}))$, are entered as listed in Table 7.

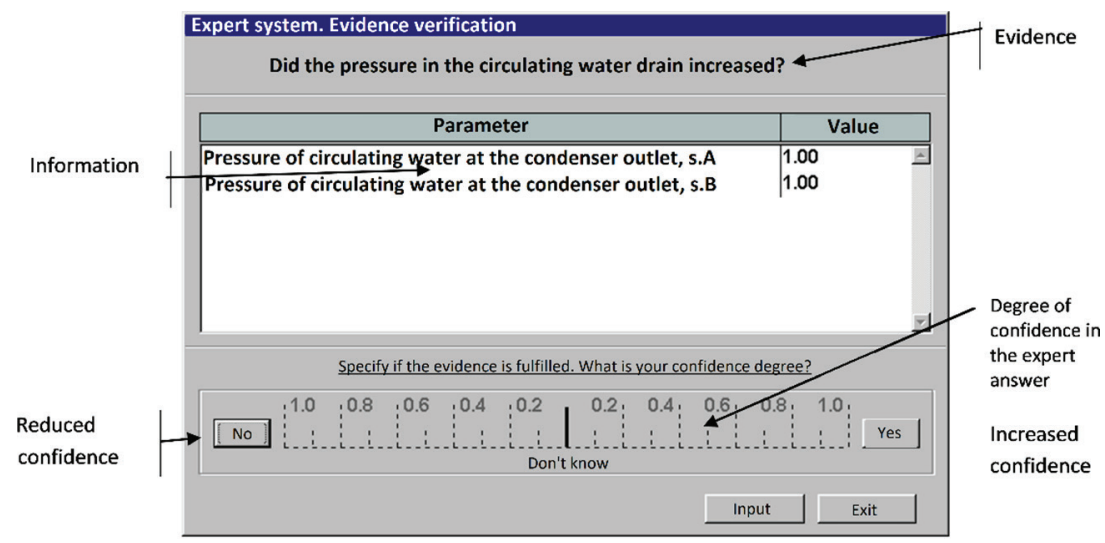

Fig. 1 Evidence processing

Figure 1: Evidence processing. 
Table 6: Initial data for diagnostics.

\begin{tabular}{lllll}
\hline № & Name & Designation & Units & Notes \\
\hline 1 & $\begin{array}{l}\text { Condensate temperature at } \\
\text { condensate pump input }\end{array}$ & $t_{c}$ & ${ }^{\circ} \mathbf{C}$ & \\
2 & $\begin{array}{l}\text { Condensate temperature at } \\
\text { ejector output }\end{array}$ & $t_{2 \mathrm{c}}$ & ${ }^{\circ} \mathrm{C}$ & Manual input \\
3 & $\begin{array}{l}\text { Ejector motivating steam } \\
\text { pressure }\end{array}$ & $\mathrm{P}_{m}$ & $\mathrm{~kg} / \mathrm{cm}^{2}$ & $\begin{array}{l}\text { Manual input } \\
\text { (indicator) for } \\
\text { ejectors A and B }\end{array}$ \\
& $\begin{array}{l}\text { Dry air ejector flow rate } \\
\text { Determined by }\end{array}$ \\
& $G_{a}$ & $\mathrm{~kg} / \mathrm{h}$ & $\begin{array}{l}\text { De ejector test } \\
\text { results }\end{array}$ \\
\hline
\end{tabular}

Table 7: List of defects.

\begin{tabular}{lll}
\hline № & Defect name & $\begin{array}{l}\text { A priori proba- } \\
\text { bility, } \mathbf{P}(\mathbf{H})\end{array}$ \\
\hline 1 & Low motivating steam consumption & 0.1 \\
2 & Inadequate flow rate of the main condensate & 0.15 \\
3 & High temperature of the main condensate & 0.15 \\
& Reduced heat transfer surface (high tube contamination or a & 0.05 \\
4 & large number of tubes plugged) & 0.15 \\
5 & Leakage of partitions in the steam space & 0.15 \\
6 & Tube system leaks & 0.25 \\
7 & Drainage clogged & 0.1 \\
8 & Flow path wear & \\
\hline
\end{tabular}

Each malfunction of the ejector has a list of signs (evidence) that correspond to it; this list is given in Table 8 .

As an example, the probabilities of evidence (malfunction signs) in the presence of a specific defect $(\mathrm{P}(\mathrm{E}: \mathrm{H}))$ and in the absence of the defect $(\mathrm{P}(\mathrm{E}:$ not $\mathrm{H}))$ are presented in Tables 9 and 10 , respectively.

\section{CONCLUSIONS}

An ES of probability type is presented for diagnostics and state estimation of components of steam turbine technological subsystems. The knowledge base is made up for rotors, bearings, turbine automatic control and protection system and for other components of the turbine unit, condensing unit equipment and other technological subsystems.

The ES permits one to diagnose the condition of various subsystems and components of the turbine unit, to troubleshoot the equipment components and to formulate recommendations about the ways and terms of defect elimination and of reducing the risk of their 
development. To do this, the system employs the experience of experts. Information from the ES can be used to adjust the turbine operation regimes and to optimize the amount and timing of equipment repair.

Table 8: List of signs.

\begin{tabular}{|c|c|c|c|}
\hline № & Evidence (sign) name & Designation & Evidence evaluation algorithm \\
\hline 1 & $\begin{array}{l}\text { High heating of the main } \\
\text { condensate in the ejector }\end{array}$ & $\Delta t_{\mathrm{ej}}$ & $t_{2 \mathrm{c}}-t_{c}>5^{\circ} \mathrm{C}$ \\
\hline 2 & $\begin{array}{l}\text { Low motivating steam pres- } \\
\text { sure in the ejector }\end{array}$ & $\mathrm{P}_{m f}$ & $\mathrm{P}_{m}<13$ \\
\hline 3 & $\begin{array}{l}\text { Water hammering in ejector } \\
\text { housing }\end{array}$ & $h$ & - \\
\hline 4 & Ejector steaming & $E_{s t}$ & $\begin{array}{l}\text { A steam-air mixture column is visible } \\
\text { from the ejector exhaust }\end{array}$ \\
\hline 5 & Ejector capacity is low & $G_{a j}$ & $G_{a}<80 \mathrm{~kg} / \mathrm{h}$ \\
\hline 6 & Ejector stage flooding & $Z$ & $\begin{array}{l}\text { When tapping the ejector housing, } \\
\text { a dull sound is heard (the housing is } \\
\text { filled with main condensate) }\end{array}$ \\
\hline 7 & $\begin{array}{l}\text { High pressure at the inlet of } \\
\text { the ejector first stage at zero } \\
\text { air flow }\end{array}$ & $P_{a s}$ & $P_{a s O}>1.5 \mathrm{kPa}$ \\
\hline
\end{tabular}

Table 9: Probabilities of evidence (malfunction signs) in the presence of a specific defect $(\mathrm{P}(\mathrm{E}: \mathrm{H}))$.

\begin{tabular}{lllllllll}
\hline $\begin{array}{l}\text { № of malfunction } \\
\text { hypothesis }\end{array}$ & & & & & & & & \\
№ of evidence & $\mathbf{1}$ & $\mathbf{2}$ & $\mathbf{3}$ & $\mathbf{4}$ & $\mathbf{5}$ & $\mathbf{6}$ & $\mathbf{7}$ & $\mathbf{8}$ \\
\hline 1 & - & 0.9 & - & - & 0.1 & 0.05 & - & - \\
2 & 0.9 & - & - & - & - & - & 0.1 & - \\
$\ldots$ & $\ldots$ & $\ldots$ & $\ldots$ & $\ldots$ & $\ldots$ & $\ldots$ & $\ldots$ & $\ldots$ \\
7 & 0.9 & 0.5 & 0.9 & 0.1 & - & - & - & 0.95 \\
\hline
\end{tabular}

Table 10: Probabilities of evidence (malfunction signs) in the absence of a specific defect (P(E:not H)).

\begin{tabular}{lllllllll}
\hline № of evidence & $\mathbf{1}$ & $\mathbf{2}$ & $\mathbf{3}$ & $\mathbf{4}$ & $\mathbf{5}$ & $\mathbf{6}$ & $\mathbf{7}$ & $\mathbf{8}$ \\
\hline 1 & - & 0.077 & - & - & 0.22 & 0.23 & - & - \\
2 & 0.12 & - & - & 0.00 & 0.00 & 0.00 & 0.23 & - \\
$\ldots$ & $\ldots$ & $\ldots$ & $\ldots$ & $\ldots$ & $\ldots$ & $\ldots$ & $\ldots$ & $\ldots$ \\
7 & 0.46 & 0.50 & 0.43 & 0.60 & - & - & - & 0.39 \\
\hline
\end{tabular}


CSD - cam-operated steam distribution device

\section{NOMENCLATURE}

$\mathrm{CU}$ - condensing unit

ES - expert system

STU - steam turbine unit

AV - adjusting valve

TAR - turbine automatic regulatory system

$\mathrm{RS}$ - rotation speed

FR - frequency response

$t_{c}, t_{s}$ - condensate temperature, saturation temperature

$\mathrm{P}_{m}$ - pressure of primary steam

$G_{a}-\ll$ dry» air flow rate

$\Delta t_{\mathrm{ej}}$ - heating of the main condensate

$G_{a j}$ - ejector capacity with 'dry' air

$P_{a s}$ - pressure at the inlet of the ejector first stage at zero air flow

$h$-water hammering in ejector housing

$E_{s t}-$ ejector steaming

$Z$ - ejector stage flooding

\section{REFERENCES}

[1] Mikhailov, V.E., Khomenok, L.A., Sudakov, A.V. \& Obukhov, S.G., On complex diagnostics and examination of the state of equipment of thermal power plants and hydropower plants. Reliability and Safety of Energy, 2(9), pp. 9-14, 2010.

[2] Andryushin, A.V., Polushkina, E.N. \& Shnyrov, E.Yu., Development of the maintenance service system in TGK and OGK after the completion of industry restructuring processes. Thermal Engineering, 1, pp. 69-73, 2010.

[3] Aronson, K.E., Brodov, Yu.M. \& Novoselov, V.B., Development of a technical condition monitoring system for a cogenerating steam turbine equipment. Thermal Engineering, 12, pp. 65-68, 2012.

[4] GOST 20911-89. Technical Diagnostics: Basic Terms and Definitions, Publishing House of Standards: M., 14 p., 1990.

[5] Uryev, E.V., Fundamentals of Reliability and Technical Diagnostics of Turbomachines, USTU: Ekaterinburg, 71 p., 1996.

[6] Hayet, S.I., Aronson, K.E., Brodov, Yu.M. \& Shempelev, A.G., Development and testing of system elements for status monitoring and diagnostics of a steam turbine condenser. Thermal Engineering, 7, pp. 67-69, 2003.

[7] Kovalev, N.A., Algorithms development for the operation and recognition of defects for automatic system of vibration diagnostics. CKTI Proceedings, 19, pp. 27-33.

[8] Mirzabekov, A.M., Haimov, V.A. \& Khrabrov, V.P., Optical diagnostic system for erosion damage of the input edges of steam turbine blades. Thermal Engineering, 4, pp. 52-56, 1991.

[9] Panov, E.V. (ed.), Artificial Intellect: Directory, Radio \& Communication: M., 1, 461 pp., 1990.

[10] Bashlykov, A.A., Expert system architecture to back up decision-making processes in fault diagnosing of thermal power station heat exchanging equipment (SPRINT). Collected volume: An Expansion of Intellectual Abilities of ACS, ed. A.A. Bashlykov, Energoatomizdat: M., pp. 5-8, 1989. 
[11] Naylor, C., Build your own Expert System, Energoatomizdat: M., 286 pp., 1991.

[12] Brooking, A., Johns, P., Forsyth, R. \& Cox, F., In: Expert Systems: Principles and Case Studies, ed. R. Forsyth. Radio \& Communication: M., 191 pp., 1987.

[13] Jackson, P., An Introduction to Expert Systems, Williams Publishers: M., 624 pp., 2001.

[14] Perminov, I.A., Orlick, V.G. \& Gordinsky, A.A., Flow path state diagnostics for steam turbines of high capacity with the use of power plant computational complexes. CKTI Transactions, 273, pp. 58-61, 1992.

[15] Brodov, Yu.M., Aronson, K.E. \& Nierenstein, M.A., The concept of diagnostics system for condensing steam turbine unit. Thermal Engineering, 7, pp. 34-38, 1997.

[16] Khaet, S.I., Aronson, K.E., Brodov, Yu, M. \& Shempelev, A.G., Development and testing of the monitoring system elements for condition control and diagnostic of steam turbine condenser. Thermal Engineering, 7, pp. 67-69, 2003. 